\title{
Static and dynamic characterization and response analysis of soils from northern India
}

\author{
Abhijit Kundu ${ }^{1}$ Nihar Ranjan Patra ${ }^{2} \cdot$ Srijit Bandyopadhyay $^{3} \cdot$ G. Rami Reddy ${ }^{4}$
}

Received: 22 August 2019 / Accepted: 12 January 2021 / Published online: 25 January 2021

(C) The Author(s) 2021 OPEN

\begin{abstract}
Experimental investigations on soil samples collected from the sites of Baraut, Noida and Mandi in North India have been performed to study the static and cyclic behavior of soil. Liquefaction potential of the sites near Himalayan range is also carried out. The SPT and downhole seismic tests have been performed for the estimation of static and dynamic properties of soil. Strain-controlled cyclic triaxial tests are also carried out on soil samples collected from the borehole at various depths up to $30 \mathrm{~m}$ for the evaluation of dynamic soil properties. The study examined the effects of parameters such as cyclic shear strain, loading frequency and overburden pressure on the cyclic behavior of the soil. One- and twodimensional dynamic response analysis has been performed on three sites. The initiation of initial liquefaction ranged from 202 to 752 cycles for the Baraut site, 212 to 722 cycles for the Noida site, and 121 to 617 cycles for the Mandi sites. The final design response spectra of the sites are obtained from 1D ground response analysis. The results from the response analysis have been compared with the reported results. The soils from the present study areas are prone to liquefaction at $10 \mathrm{~m}$ to $15 \mathrm{~m}$ from the ground surface.
\end{abstract}

Keywords Ground response - Liquefaction - Shear modulus - Damping · PGA · PGD · Pore water pressure

$\begin{array}{ll}\text { Abbreviations } \\ \text { 1D } & \text { One-dimensional } \\ \text { 2D } & \text { Two-dimensional } \\ \text { 3D } & \text { Three-dimensional } \\ a_{\max } & \text { Maximum acceleration } \\ c & \text { Cohesion } \\ C_{\mathrm{u}} & \text { Coefficient of uniformity } \\ C_{\mathrm{c}} & \text { Coefficient of curvature } \\ \mathrm{CL} & \text { Clay of low plasticity } \\ \mathrm{Cl} & \text { Clay of medium plasticity } \\ \mathrm{CRR} & \text { Cyclic stress ratio } \\ \mathrm{CRR} & \text { Cyclic resistance ratio } \\ \mathrm{EPPR} & \text { Excess pore pressure ratio } \\ G & \text { Specific gravity } \\ \mathrm{LL} & \text { Liquid limit }\end{array}$

ML Silt of low plasticity

p Mean stress

PGA Peak ground acceleration

PGD Peak ground displacement

PI Plasticity Index

PL Plastic limit

$9 \quad$ Deviatoric stress

Sigma3 Confining pressure

SP Poorly graded sand

SPT-N Standard penetration resistance value

USCS Unified soil classification system

$V_{s} \quad$ Shear wave velocity

$\Phi \quad$ Friction angle

\begin{abstract}
$\triangle$ Nihar Ranjan Patra, nrpatra@iitk.ac.in; Abhijit Kundu, akundu@iitk.ac.in; Srijit Bandyopadhyay, srijit@barc.gov.in; G. Rami Reddy, rssred@barc.gov.in | ${ }^{1}$ Department of Civil Engineering, Indian Institute of Technology Kanpur, Kanpur 208016, India. ${ }^{2}$ Geotechnical Engineering Division, Department of Civil Engineering, Indian Institute of Technology Kanpur, Kanpur-208016, India. ${ }^{3}$ Bhabha Atomic Research Centre, Board of Research in Nuclear Sciences (BRNS), Mumbai, India. ${ }^{4}$ Homi Bhabha National Institute, Bhabha Atomic Research Centre, Board of Research in Nuclear Sciences (BRNS), Mumbai, India.
\end{abstract}




\section{Introduction}

Recent major earthquakes such as the 2015 earthquake in Nepal $\left(M_{\mathrm{w}}-7.8\right)$, the 2013 earthquake in Pakistan $\left(M_{\mathrm{w}}-8.2\right)$, the 2014 earthquake in China $\left(M_{\mathrm{w}}-6.2\right)$, the 2012 earthquake in Iran $\left(M_{\mathrm{w}}-6.4\right)$, the 2011 earthquake in Turkey $\left(M_{\mathrm{w}}-7.2\right)$, the 2011 earthquake in Japan $\left(M_{\mathrm{w}}-8.9\right)$, the 2010 earthquake in China $\left(M_{\mathrm{w}}-6.9\right)$, and the 2010 earthquake in Haiti $\left(M_{\mathrm{w}}-7.0\right)$ have resulted in a huge loss of life and the destruction of important structures [1]. Such earthquakeinduced damage of major structures has attracted more attention among civil engineers and researchers.

Researchers have carried out deterministic and probabilistic seismic hazard analyses and seismic microzonation studies in different cities in India (Kandpal et al. [2], Anbazhagan et al. [3] Sharma et al. [4]). Wiemer et al. [5] conducted site-specific seismic hazard analyses of nuclear power plants. A few site-specific seismic response analysis studies have been carried out to better understand the risk related to earthquake-induced damage and liquefaction, including one-dimensional ground response analyses conducted for liquefaction analysis (Rao et al. [6]; Kumar et al. [7]). Jishnu et al. [8] carried out one- and two-dimensional ground response analyses of Kanpur. They reported the soils at deeper depth are prone to liquefaction. Naik et al. [9] conducted one- and two-dimensional dynamic response analyses of soils from Rudrapur and Khatima sites located in the Uttarakhand state of northern India. They reported the soils at shallow depth are prone to liquefaction. Baraut, Noida and Mandi sites are located very close to the seismically active Himalayan Frontal Thrust. A few studies on response analysis of soils have been reported nearby the Indo-Gangetic plains. However, no field study and response analysis have been reported in these sites near to the earthquake recording stations of Baraut, Noida and Mandi sites. Considering the above facts, field study, static and dynamic tests have been conducted on the soils from Baraut, Noida and Mandi sites to study the variations in SPT-N values, shear wave velocity values, shear strength of soil samples and dynamic properties of soil samples with depth. One-dimensional response analysis has been conducted on soils based on field study. Also, two-dimensional analysis has been conducted on soils to examine the variation in peak ground acceleration (PGA), peak ground displacement (PGD) and excess pore pressure ratio (EPPR) using the scale-down ground motion data of three earthquakes of Himalayan origin (i.e., Chamba, Chamoli and Uttarkashi). The liquefaction potentials of soils from present study have been compared with the reported results adjoining to Indo-Gangetic plain.

\section{Methodology}

\subsection{Site selection}

This study considered three sites: Baraut, Noida and Mandi in northern India (Fig. 1). Baraut and Noida sites are located in the Ganga-Yamuna alluvial plain. Baraut is located at the coordinates of $29.6^{\circ} \mathrm{N}, 77.16^{\circ} \mathrm{E}$ [10]. The average elevation of Baraut site is $231 \mathrm{~m}$. The geological formations of soils from Baraut and Noida sites are quaternary alluvium consisting of sands of various grades, silt, clay and Kankar. Noida is located at the coordinates of $28.5^{\circ} \mathrm{N}, 77.5^{\circ} \mathrm{E}$ [10]. Mandi is located at the coordinates of $30.7^{\circ} \mathrm{N}, 76.8^{\circ} \mathrm{E}$ [11] and is near the foothills of the Shivalik range of the Himalayas in Northwest India. The average elevation of Mandi site is $321 \mathrm{~m}$. The subsurface of the Mandi region is comprised of beds of boulders, pebbles, gravel, and silt.
Fig. 1 Map showing the locations of Baraut, Noida and Mandi sites of northern India

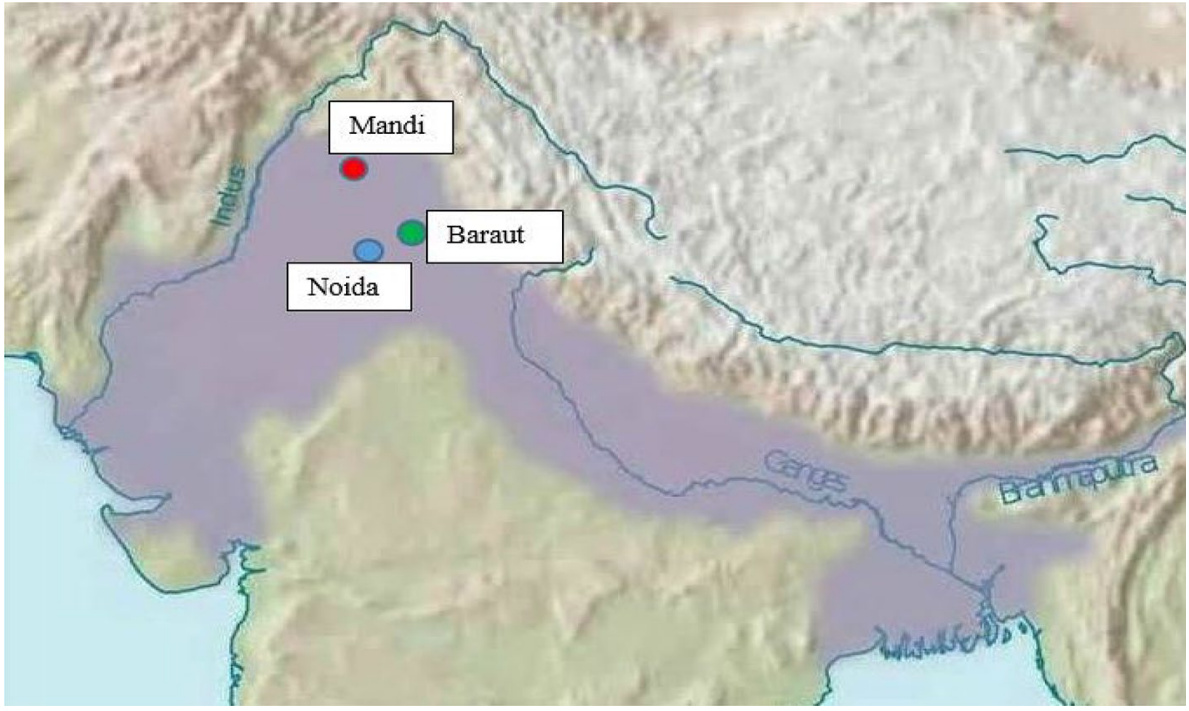


All three sites of this study belong to the seismic zone IV. The present study area is subjected to seismic threats from major faults like the Himalayan Frontal Thrust (HFT) and Main Boundary Thrust (MBT). Hence, it is necessary to study the site-specific dynamic response analysis regarding PGA, PGD, and EPPR values before constructing any major structures like bridges, high-rise buildings, and power plants.

\subsection{Field and laboratory study}

\subsubsection{Field test}

Standard penetration tests (SPT) and seismic downhole tests were performed on soils at the Baraut, Noida and Mandi sites to determine the SPT-N value and shear wave velocity $\left(V_{s}\right)$. At each site, two boreholes were drilled at a spacing of $3 \mathrm{~m}$ to $4 \mathrm{~m}$. The first borehole was used to conduct SPT and collect representative and undisturbed soil samples. All the soil samples were collected at an interval of $1.5 \mathrm{~m}$ from the ground surface to a depth of $30 \mathrm{~m}$. For the Baraut site, undisturbed samples were collected at depths of $1.5 \mathrm{~m}, 3.0 \mathrm{~m}, 4.5 \mathrm{~m}, 6 \mathrm{~m}$ and $7.5 \mathrm{~m}$. For the Noida site, undisturbed samples were collected at depths of $1.5 \mathrm{~m}, 3.0 \mathrm{~m}, 4.5 \mathrm{~m}, 6 \mathrm{~m}, 7.5 \mathrm{~m}, 15 \mathrm{~m}$ and $16.5 \mathrm{~m}$. For the Mandi site, undisturbed sample tubes were collected at depths of $1.5 \mathrm{~m}, 3.0 \mathrm{~m}, 4.5 \mathrm{~m}$ and $16.5 \mathrm{~m}$. It was not possible to collect undisturbed sample tubes throughout the depth because of the presence of fine sand and the water table. The second borehole was used to conduct a downhole test. SPT was carried out according to the Indian standard of IS 2131-1981 [12], which is similar to the ASTM D1586 [13] standard. Seismic downhole tests were performed according to ASTM D7400-08 [14].

\subsubsection{Basic geotechnical test}

Basic geotechnical tests were carried out on the collected representative and undisturbed soil samples. Detailed soil classification was performed according to the Indian standard IS 1498 (1970) [15], which is similar to ASTM 2487 [16]. Various tests were used for soil classification. The specific gravity test was conducted according to the Indian standard IS 2720 (Part 3):1980 [17]. The grain size distribution analysis was carried out according to the Indian standard IS 2720 (part 4):1985 [18]. Liquid limit and plastic limit tests were carried out according to Indian standard IS 2720 (part 5):1985 [19]. Consolidation tests were performed according to IS 2720 (part 15):1986 [20]. The unconsolidated undrained triaxial test (UU) was carried out following IS 2720 (part 11):1993 [21]. Data from basic tests were subsequently used in the response analysis.

\subsubsection{Cyclic triaxial test}

Strain-controlled cyclic triaxial tests were carried out on the collected disturbed and undisturbed soil samples from the three sites. For the disturbed soil, the cylindrical samples were made by two different techniques depending upon the soil type tested. The moist tamping method (Ladd 1978) [22] was applied to the silty soil sample, while the vacuum method (Mulilis et al. 1977) [23] was adopted for the sandy soil. Soil samples that were $50 \mathrm{~mm} \times 100 \mathrm{~mm}$ were used for the cyclic triaxial tests. Fully digitalized and automated triaxial test system (Model No: HS 28.610) [24] provided by Hydraulic and Engineering Instruments, New Delhi, India, was used for this study. All tests were performed as per ASTM D5311 [25].

\subsection{Ground response analysis}

The bedrock of three sites (Baraut, Noida and Mandi) close to the Himalayas in northern India is located at medium to high depth. Hence, soil strata $30 \mathrm{~m}$ below the ground surface are considered for analysis. Both one- and twodimensional response analyses were carried out for the study area.

\subsubsection{Scale-down ground motion data}

Onsite recorded ground motion data of the Baraut earthquake $\left(M_{\mathrm{w}}-4.1\right)$ and far-source recorded data of ground motion like Chamba $\left(M_{\mathrm{w}}-5.1\right)$, Chamoli $\left(M_{\mathrm{w}}-6.4\right)$ and Uttarkashi $\left(M_{\mathrm{w}}-6.5\right)$ earthquakes were taken for the numerical analysis. In situ data were collected from the Baraut seismic stations. Far-source ground motions data were collected from the COSMOS site. These earthquakes' ground motion data were used because these earthquakes were of Himalayan origin. The distance between the epicenter of these earthquakes and that of the study area is quite high. For this reason, scale-down ground motion data using Indian standard IS 1893-1 (2002) were used instead of original ground motion data.

\subsubsection{One-dimensional response analysis}

In one-dimensional ground response analysis, the factor of safety against liquefaction of soil layers was calculated to a depth of $30 \mathrm{~m}$. This method is based on the estimated cyclic resistance ratio (CRR) and cyclic stress ratio (CSR). The CRR value is calculated from the fine content corrected SPT value $\left(N_{1}\right)_{60 . c s}$. The CSR value is calculated from the overburden stress ratio and normalized peak ground acceleration value. The factor of safety against liquefaction is the ratio of the cyclic resistance to cyclic stress ratios. If 
the factor of safety value is less than 1, then it is assumed that soil is prone to liquefaction (Seed and Idriss 1971) [26].

\subsubsection{Two-dimensional response analysis}

The soil columns used in the analysis were discretized into a finite number of nodes. The typical soil column used in this analysis is shown in Fig. 2. An effective stressbased numerical model is used for the response analysis because it can simulate the generation and development of excess pore pressure. The numerical simulation of the $2 \mathrm{D}$ response analysis is performed by using the open source software program OpenSees, developed by Fenves et al. [27]. Plane strain condition proposed by Biot [28] is considered in the $2 \mathrm{D}$ response analysis of fully coupled porous media. Pressure-dependent and pressure-independent multiyield constitutive material model available in OpenSees is used for the simulation of response analysis for cohesionless and cohesive materials, respectively. The elastic half-space used in the numerical model is simulated by using Lysmer and Kuhlemeyer [29] dashpot. Solid-fluid fully coupled elements are used to simulate the dynamic response of soil columns under fully undrained condition. The Nine Four Node Quad u-p element available in the OpenSees software package is used. It is a plane strain element in a rectangular shape. There are nine nodes in this element. In the Nine Four Node Quad u-p element, the degree of freedom of the interior nodes is 2 and the degree of freedom of the corner nodes is 3 . For the interior nodes, both degrees of freedom are in translational mode. For the corner nodes, there is an additional degree of freedom for pore water pressure. The plasticity of the soil material is simulated by using a multiyield surface concept [30-32]. In material modeling, Drucker-Prager-type surfaces are used for pressure-dependent multiyield material and von Mises-type surfaces are used for pressure-independent

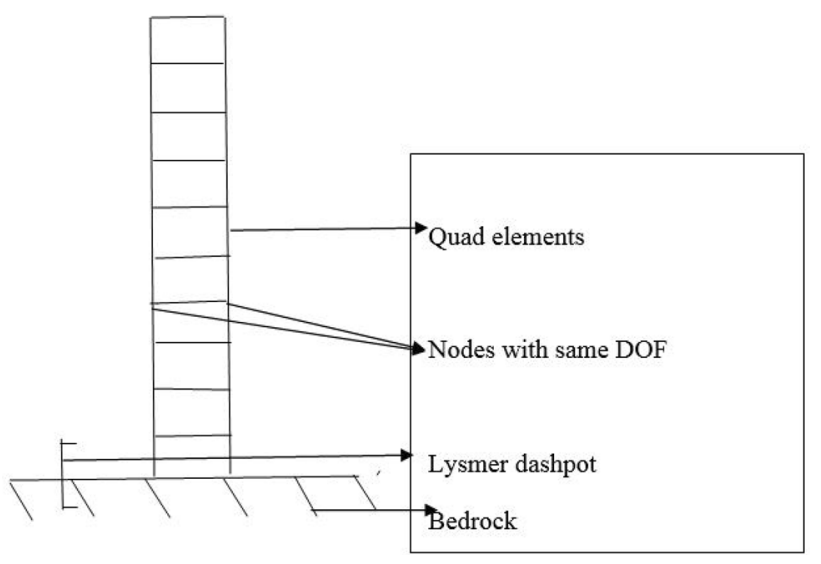

Fig. 2 OpenSees soil model for 2D effective stress-based site response analysis multiyield material [33]. The largest element used in this analysis in the direction of wave propagation is one-eighth of the wavelength of the shortest wave propagating in soil medium [34]. The bulk density, bulk modulus, shear modulus, cohesion and the friction angle of different soil layers are used as the input data for the numerical analysis. Also, the bulk density and shear wave velocity of bed rock material and the acceleration time history of synthetic ground motion are used as input data. Acceleration, displacement and excess pore pressure ratio are the results of the $2 \mathrm{D}$ response analysis.

\section{Results and discussions}

\subsection{Field tests and laboratory tests results}

Field tests like the standard penetration test and the downhole seismic test were performed. Basic geotechnical tests including consolidation test and unconsolidated undrained triaxial tests were performed. Advanced tests like the strain-controlled cyclic triaxial tests were also performed.

The ranges of SPT-N values are 14-34 for Baraut site, 12-32 for Noida site and 12-36 for Mandi site. The ranges of shear wave velocity values are $128-545 \mathrm{~m} / \mathrm{s}$ for Baraut site, $203-505 \mathrm{~m} / \mathrm{s}$ for Noida site and $114-608 \mathrm{~m} / \mathrm{s}$ for Mandi site.

Based on the laboratory study, the soil is classified according to the Indian standard. The ranges of bulk unit weight of the soils are $17-19 \mathrm{kN} / \mathrm{m}^{3}$ for the Baraut and Noida sites and $17-20 \mathrm{kN} / \mathrm{m}^{3}$ for Mandi site. The soils from Baraut site contain 0 to $99 \%$ sand, 0 to $64 \%$ silt and 0 to $28 \%$ clay. The cohesion value of soil from the Baraut site is 0 to $90 \mathrm{kPa}$ and the friction angle is 2 to 40 degrees. The soils from Noida site contain 0 to $99 \%$ sand, 0 to $60 \%$ silt and 0 to $25 \%$ clay. The cohesion value is 0 to $80 \mathrm{kPa}$ and the friction angle of soil from Noida site is 2 to 40 degrees. The soils from Mandi site contain 3 to $82 \%$ sand, 10 to $72 \%$ silt and 3 to $36 \%$ clay. For Mandi soil, the cohesion value is varying from 20 to $130 \mathrm{kPa}$ and its friction angle is 17 to 30 degrees. The groundwater table is located at $9 \mathrm{~m}$ below from the ground surface for three sites.

Typical soil classification of soil from Baraut site is shown in Table 1. The soils from Baraut and Noida sites are mainly of the SP (poorly graded sand) type. Besides, the soil from Mandi site is mainly ML (Silt of low plasticity) type. The predominance of sand and silt in Baraut and Noida sites indicates that soil strata are river deposits.

Both consolidation and undrained triaxial tests were conducted on the soil samples collected from these sites. The compression index of the soil sample is determined from the consolidation test. A typical graph showing 


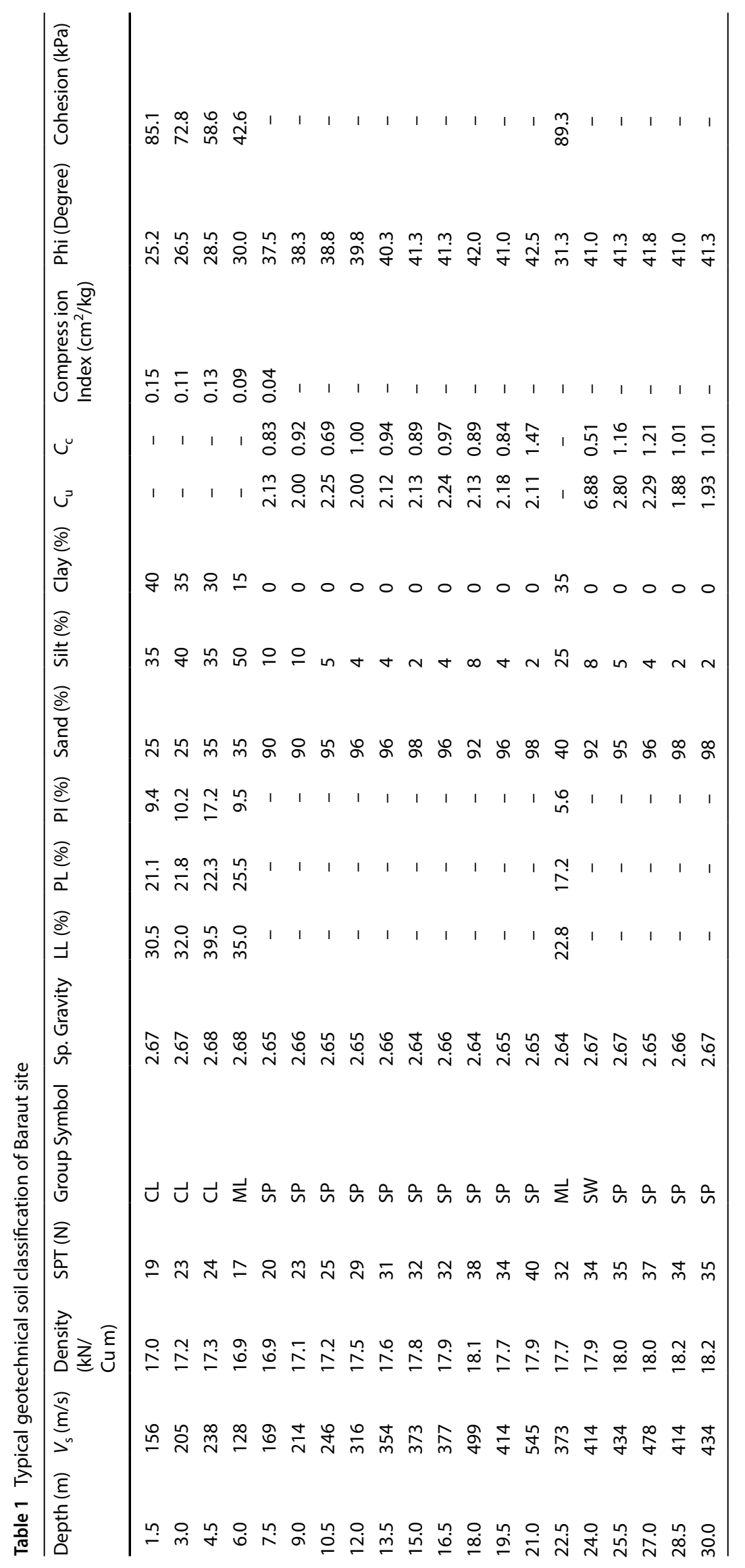




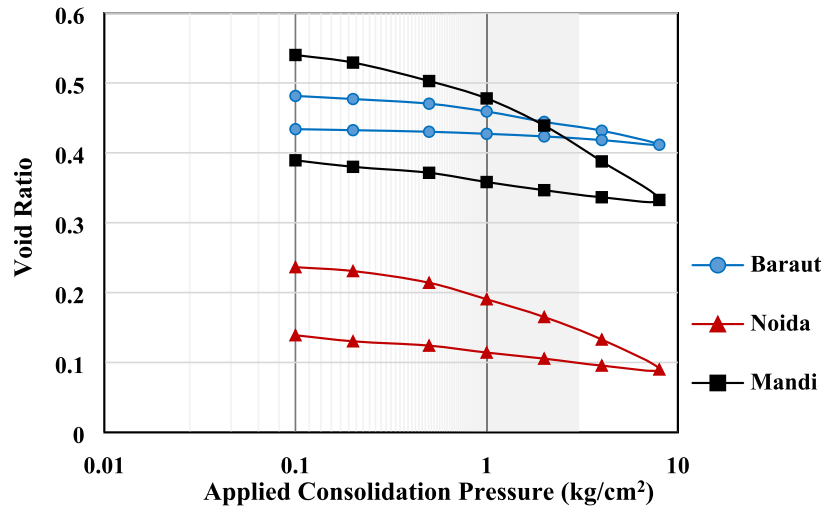

Fig. 3 Typical plot showing variation in void ratio with load for present study area

the variation in void ratio with effective stress is shown in Fig. 3. The range of compression index of soil ranges 0.04-0.16. It indicates that the soil from three sites is low to medium compressible. Consolidated undrained (CU) triaxial tests are performed to estimate the undrained cohesion and friction angle values. A typical graph showing the variation in deviatoric stress with axial strain is given in Fig. 4. Typical p-q plot is shown in Fig. 5 for Baraut, Noida and Mandi soils at $3 \mathrm{~m}$ depth. The failure strain ranges from $12.5 \%$ to $20.2 \%$.

\subsubsection{Strain-controlled cyclic triaxial test result}

The variation in deviatoric stress and excess pore pressure ratio with number of cycles is studied. Typical table showing the dynamic properties of soil from Baraut site is given in Table 2. The results are shown in Fig. 6 for soil from Baraut site. The required numbers of loading cycles for initial liquefaction of soil are 202-752, 212-722 and 121-617 for soil collected from the sites of Baraut, Noida and Mandi, respectively. The ranges of shear modulus value of soil are $852-14,160 \mathrm{kPa}$ for Baraut site, $1512-22,440 \mathrm{kPa}$ for Noida site and 2530-20,045 kPa for Mandi site. The ranges of damping ratio values of soil are 0.16 to 0.36 for Baraut

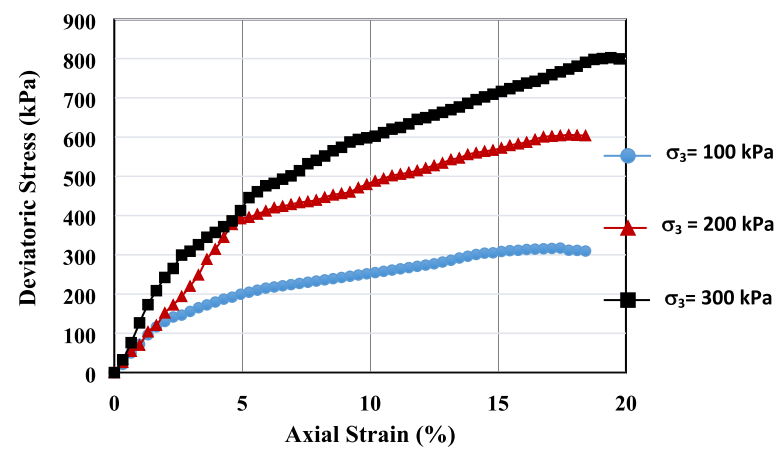

Fig. 4 Typical stress-strain curve for soil from Baraut site

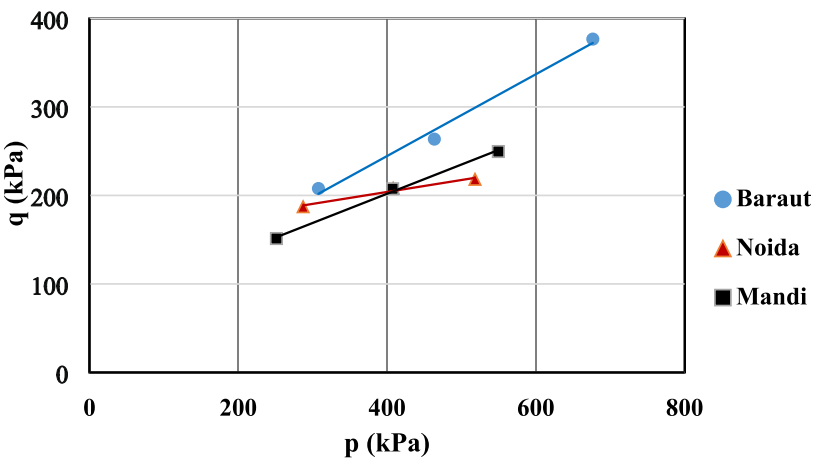

Fig. 5 p-q plot for Baraut, Noida and Mandi soil at $3 \mathrm{~m}$ depth

and Noida sites and 0.13 to 0.39 for Mandi site. The test results lead to the conclusion that Noida soil is the stiffest and Baraut soil is the softest. Mandi soil has maximum damping ratio. The increment in the required number of loading cycles for initial liquefaction is around 5\%-42\% for the Baraut site compared to the Noida and Mandi site. The shear modulus is increased by $58 \%-78 \%$ for Noida site compared to the Baraut site.

\subsection{Results of response analysis}

In this study, one-dimensional response analysis is performed based on the cyclic resistance ratio and cyclic stress ratio approach. Two-dimensional response analysis is performed by using an open source finite elementbased software program, OpenSees.

\subsubsection{Results of $1 \mathrm{D}$ response analysis}

In 1D response analysis, the factor of safety against liquefaction of soil layers is calculated to the depth of $30 \mathrm{~m}$ from the ground surface at $1.5-\mathrm{m}$ intervals. The soil layer from $13.5 \mathrm{~m}$ to $15.0 \mathrm{~m}$ at the Baraut site is prone to liquefaction. For Noida site, the soil layer from $10.5 \mathrm{~m}$ to $15.0 \mathrm{~m}$ is prone to liquefaction. In both sites, liquefaction is attributable to the presence of loose sand. The soil layer at the Mandi site is not prone to liquefaction. The final design response spectra are plotted from the results of the 1D ground response analysis. The variation in spectral displacement, spectral velocity and spectral acceleration with time period for Baraut site is shown in Fig. 7a, b and c, respectively. It is observed that for a particular earthquake magnitude, the maximum spectral displacement, spectral velocity and spectral acceleration were achieved for $5 \%$ damped elastic response. Also, for a particular damping ratio, the maximum spectral displacement, spectral velocity and spectral acceleration were achieved for Uttarkashi earthquake. 
Table 2 Typical dynamic soil properties of Baraut site

\begin{tabular}{|c|c|c|c|c|c|}
\hline Depth (m) & $\begin{array}{l}\text { Strain ampli- } \\
\text { tude }(\mathrm{mm})\end{array}$ & $\begin{array}{l}\text { Shear modu- } \\
\text { lus }(\mathrm{kPa})\end{array}$ & Damping ratio & Failure cycle & Poisson's ratio \\
\hline \multirow[t]{3}{*}{1.5} & 0.2 & 2530 & 0.238 & 265 & 0.42 \\
\hline & 0.3 & 2332 & 0.228 & 227 & 0.42 \\
\hline & 0.4 & 850 & 0.315 & 178 & 0.42 \\
\hline \multirow[t]{3}{*}{3} & 0.2 & 2536 & 0.322 & 281 & 0.44 \\
\hline & 0.3 & 2336 & 0.215 & 241 & 0.44 \\
\hline & 0.4 & 2004 & 0.242 & 158 & 0.44 \\
\hline \multirow[t]{3}{*}{4.5} & 0.2 & 9236 & 0.306 & 539 & 0.42 \\
\hline & 0.3 & 8125 & 0.387 & 448 & 0.42 \\
\hline & 0.4 & 4661 & 0.227 & 407 & 0.42 \\
\hline \multirow[t]{3}{*}{6} & 0.2 & 9875 & 0.312 & 568 & 0.43 \\
\hline & 0.3 & 8056 & 0.364 & 457 & 0.43 \\
\hline & 0.4 & 4292 & 0.226 & 433 & 0.43 \\
\hline \multirow[t]{3}{*}{7.5} & 0.2 & 5804 & 0.426 & 506 & 0.36 \\
\hline & 0.3 & 3905 & 0.215 & 458 & 0.36 \\
\hline & 0.4 & 3800 & 0.348 & 366 & 0.36 \\
\hline \multirow[t]{3}{*}{9} & 0.2 & 6253 & 0.304 & 538 & 0.38 \\
\hline & 0.3 & 5887 & 0.234 & 480 & 0.38 \\
\hline & 0.4 & 4320 & 0.298 & 367 & 0.38 \\
\hline \multirow[t]{3}{*}{10.5} & 0.2 & 8908 & 0.25 & 658 & 0.36 \\
\hline & 0.3 & 6996 & 0.299 & 592 & 0.36 \\
\hline & 0.4 & 5420 & 0.42 & 558 & 0.36 \\
\hline \multirow[t]{3}{*}{12} & 0.2 & 8930 & 0.264 & 692 & 0.37 \\
\hline & 0.3 & 6254 & 0.317 & 643 & 0.37 \\
\hline & 0.4 & 4857 & 0.411 & 554 & 0.37 \\
\hline \multirow[t]{3}{*}{13.5} & 0.2 & 11,326 & 0.224 & 708 & 0.36 \\
\hline & 0.3 & 6128 & 0.421 & 565 & 0.36 \\
\hline & 0.4 & 2512 & 0.305 & 540 & 0.36 \\
\hline \multirow[t]{3}{*}{15} & 0.2 & 10,502 & 0.234 & 697 & 0.37 \\
\hline & 0.3 & 7214 & 0.402 & 578 & 0.37 \\
\hline & 0.4 & 2144 & 0.323 & 558 & 0.37 \\
\hline \multirow[t]{3}{*}{16.5} & 0.2 & 10,044 & 0.258 & 678 & 0.36 \\
\hline & 0.3 & 8155 & 0.202 & 611 & 0.36 \\
\hline & 0.4 & 6404 & 0.25 & 557 & 0.36 \\
\hline \multirow[t]{3}{*}{18} & 0.2 & 9800 & 0.242 & 548 & 0.37 \\
\hline & 0.3 & 7254 & 0.28 & 454 & 0.37 \\
\hline & 0.4 & 6211 & 0.245 & 413 & 0.37 \\
\hline \multirow[t]{3}{*}{19.5} & 0.2 & 9928 & 0.452 & 558 & 0.36 \\
\hline & 0.3 & 9282 & 0.262 & 488 & 0.36 \\
\hline & 0.4 & 7324 & 0.214 & 433 & 0.36 \\
\hline \multirow[t]{3}{*}{21} & 0.2 & 9058 & 0.424 & 549 & 0.35 \\
\hline & 0.3 & 9002 & 0.209 & 458 & 0.35 \\
\hline & 0.4 & 7605 & 0.261 & 417 & 0.35 \\
\hline \multirow[t]{3}{*}{22.5} & 0.2 & 8878 & 0.413 & 540 & 0.36 \\
\hline & 0.3 & 8608 & 0.218 & 450 & 0.36 \\
\hline & 0.4 & 7702 & 0.285 & 348 & 0.36 \\
\hline \multirow[t]{3}{*}{24} & 0.2 & 12,345 & 0.295 & 253 & 0.38 \\
\hline & 0.3 & 9632 & 0.263 & 439 & 0.38 \\
\hline & 0.4 & 8732 & 0.23 & 354 & 0.38 \\
\hline \multirow[t]{2}{*}{25.5} & 0.2 & 13,114 & 0.285 & 548 & 0.42 \\
\hline & 0.3 & 11,456 & 0.186 & 482 & 0.42 \\
\hline
\end{tabular}


Table 2 (continued)

\begin{tabular}{llllll}
\hline Depth $(\mathrm{m})$ & $\begin{array}{l}\text { Strain ampli- } \\
\text { tude }(\mathrm{mm})\end{array}$ & $\begin{array}{l}\text { Shear modu- } \\
\text { lus }(\mathrm{kPa})\end{array}$ & Damping ratio & Failure cycle & Poisson's ratio \\
\hline \multirow{3}{*}{27} & 0.4 & 8106 & 0.273 & 444 & 0.42 \\
& 0.2 & 15,028 & 0.341 & 554 & 0.36 \\
& 0.3 & 9826 & 0.378 & 457 & 0.36 \\
28.5 & 0.4 & 8788 & 0.227 & 341 & 0.36 \\
& 0.2 & 14,452 & 0.288 & 518 & 0.37 \\
& 0.3 & 11,858 & 0.192 & 470 & 0.37 \\
30 & 0.4 & 10,926 & 0.262 & 378 & 0.37 \\
& & & & & \\
& 0.2 & 14,464 & 0.348 & 522 & 0.36 \\
& 0.3 & 10,122 & 0.398 & 452 & 0.36 \\
& 0.4 & 9802 & 0.402 & 354 & 0.36 \\
\hline
\end{tabular}

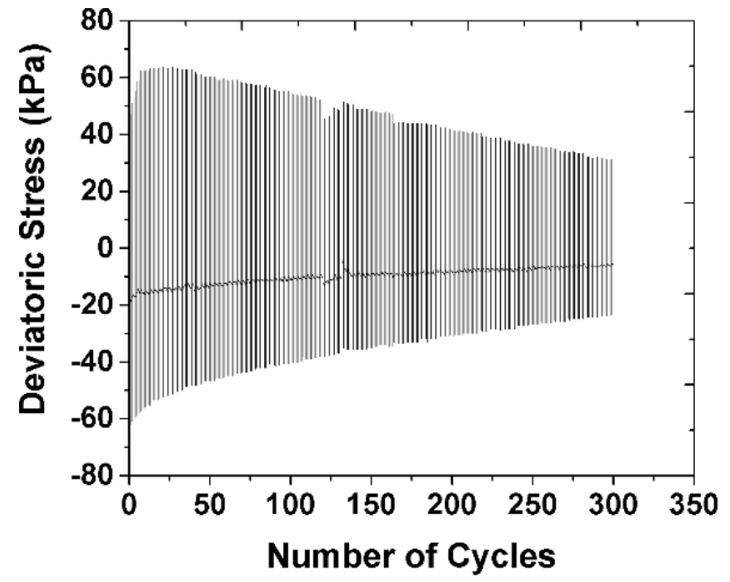

(a)

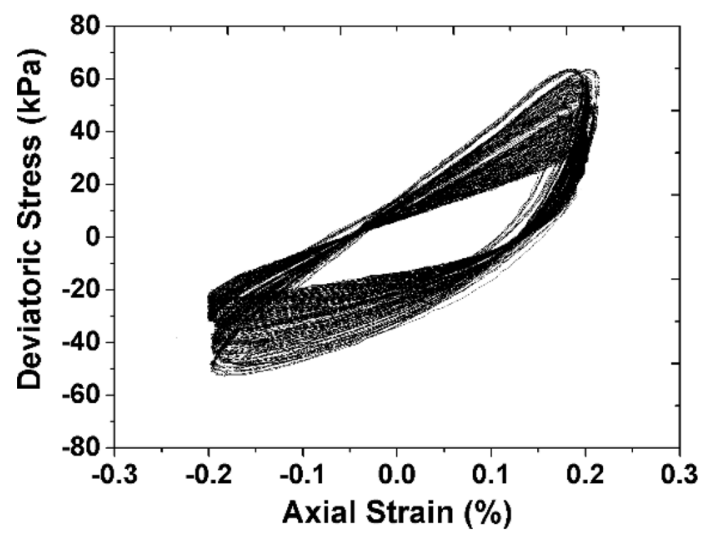

(c)

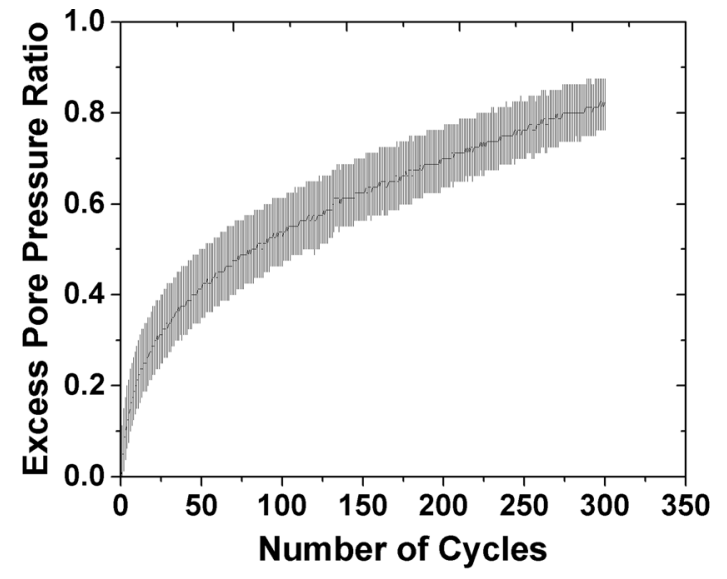

(b)

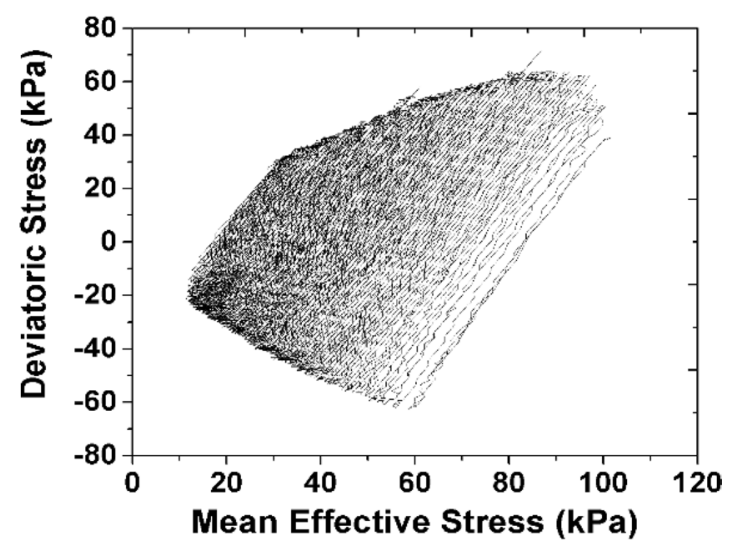

(d)

Fig. 6 Typical plot showing a variation of deviatoric stress with number of cycles, $\mathbf{b}$ variation of excess pore pressure ratio with number of cycles, $\mathbf{c}$ variation of deviatoric stress with axial strain, $\mathbf{d}$ variation of deviatoric stress with mean effective stress 

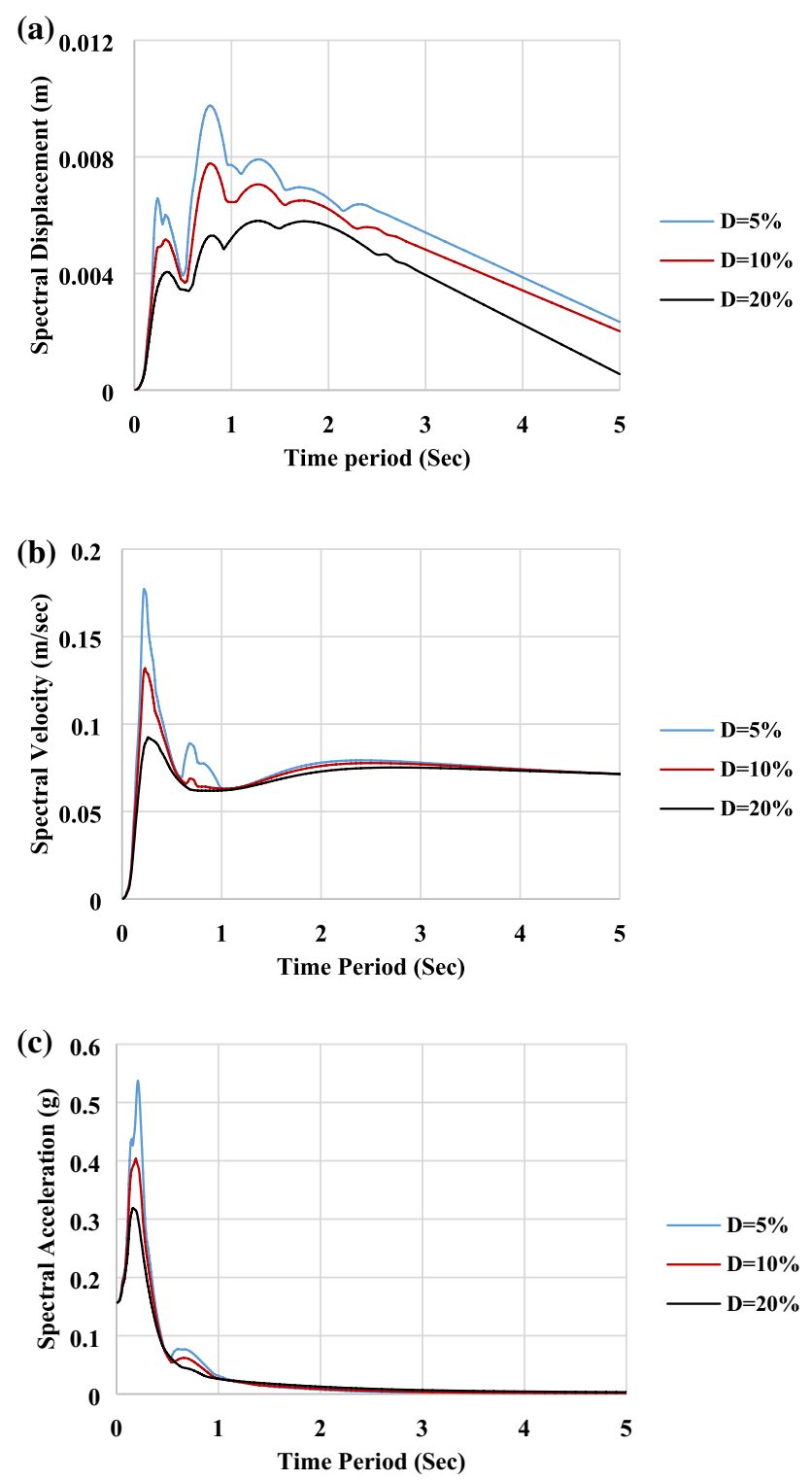

Fig. 7 a Variation in spectral displacement with time period for Baraut site. b Variation in spectral velocity with time period for Baraut site. c Variation in spectral acceleration with time period for Baraut site

\subsubsection{Results of 2D response analysis}

$2 \mathrm{D}$ response analysis was conducted on soils from Baraut, Noida and Mandi sites. Parameters such as peak ground acceleration (PGA), peak ground displacement (PGD) and excess pore pressure ratio (EPPR) are estimated for the three sites using the Baraut earthquake $\left(M_{\mathrm{w}}=4.1\right)$, the Chamba earthquake $\left(M_{\mathrm{w}}-5.1\right)$, the Chamoli earthquake $\left(M_{\mathrm{w}}-6.4\right)$ and the Uttarkashi earthquake $\left(M_{\mathrm{w}}-6.5\right)$.

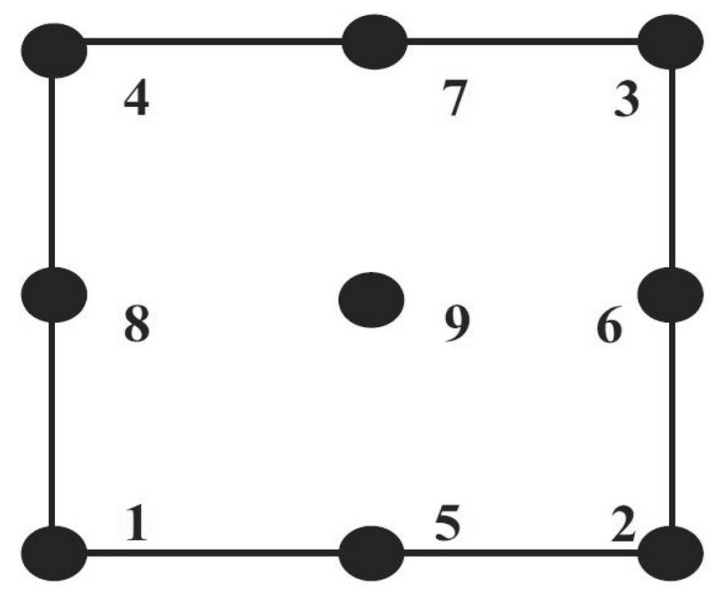

Fig. 8 Diagram of 9_4_QuadUP element

\subsubsection{Validation of model}

The numerical model developed using OpenSees was validated by modeling the undrained cyclic triaxial test. The validity of the numerical model was done by comparing results with the experimental cyclic triaxial test on a Baraut soil sample. It is observed that the Baraut soil consists mainly of poorly graded sand. For the constitutive modeling of the soil material, pressure-dependent multiyield material is used [35]. A 9_4_QuadUP element is used for the simulation of the soil material subjected to undrained cyclic loading. The diagram of a single 9_4_QuadUP element is shown in Fig. 8. The nonlinear dynamic simulation is performed in two stages. In the first stage, the element is allowed for isotropic consolidation. In the next stage, shearing is applied to the soil element in undrained condition. The strain-controlled undrained cyclic triaxial test for soil collected from the Baraut site at $12 \mathrm{~m}$ depth is performed at $0.2 \%$ axial strain, $1 \mathrm{~Hz}$ loading frequency and $110 \mathrm{kPa}$ effective confining pressure. The comparison of numerical and experimental results in terms of variation in deviatoric stress with axial strain, variation in deviatoric stress with mean effective stress and variation in EPPR with number of cycles is shown in Fig. 9a, b and c, respectively. It may be noted that the results from the numerical model using OpenSees have a very good agreement with the experimental results performed on the Baraut soil sample with an error of $\pm 10-12 \%$ and hence validates the $2 D$ response analysis.

\subsubsection{Variations in PGA, PGD and EPPR with depth}

Table 3 shows the depthwise variation in PGA for soils from the sites of Baraut, Noida and Mandi. The variation in acceleration with time for Baraut site for Chamba $\left(M_{\mathrm{w}}=5.1\right)$ earthquake at the surface is shown in Fig. 10a. The 


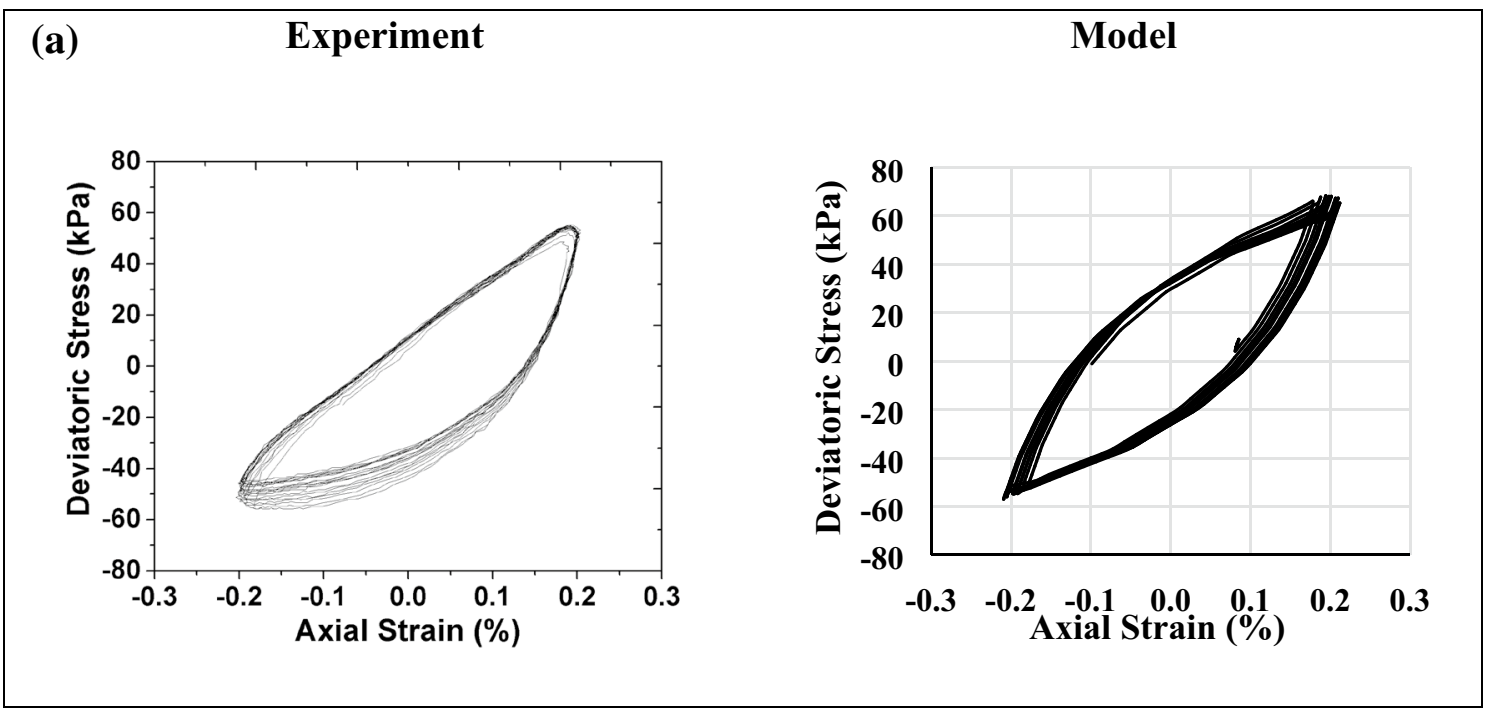

(b) Experiment Model
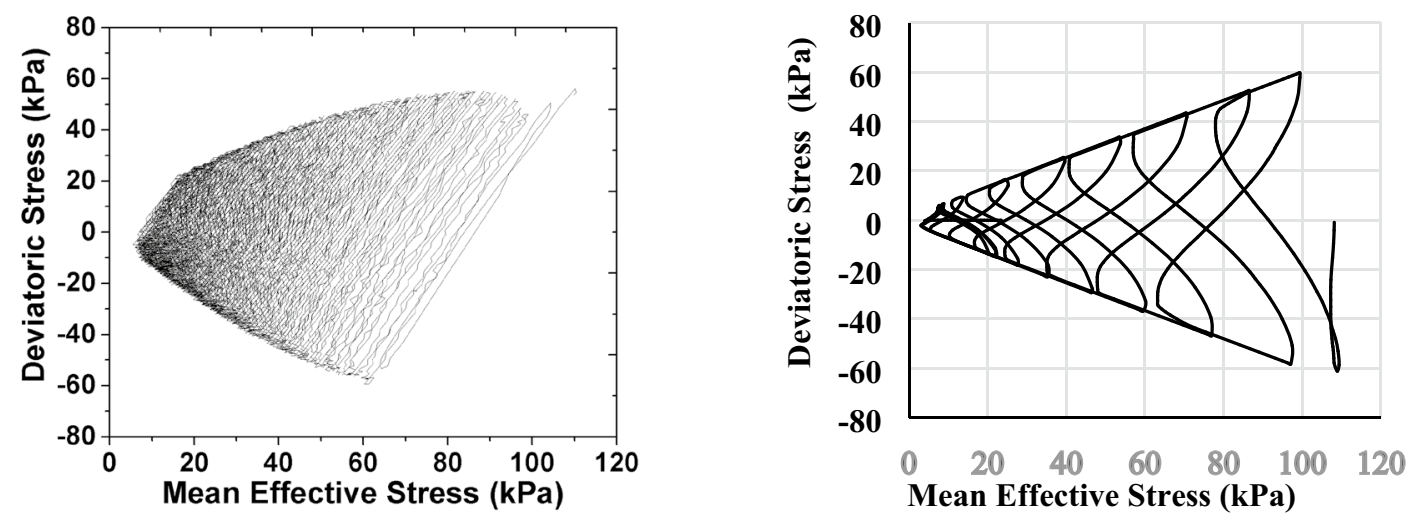

(c)

Experiment

Model
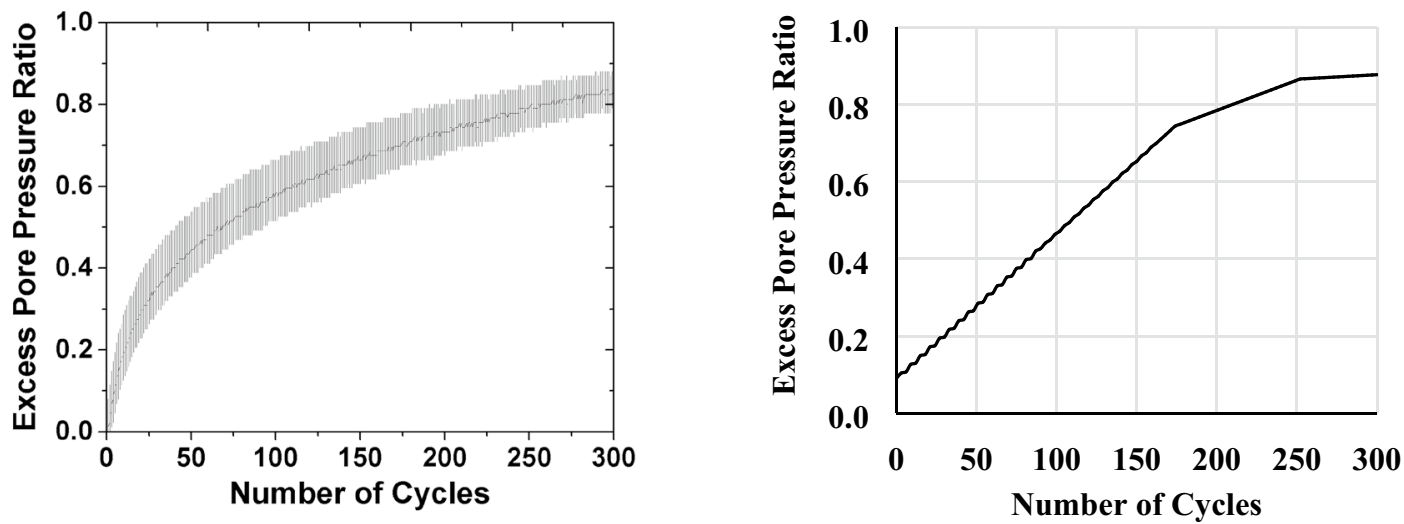
4 Fig. 9 a Recorded and computed results of the variation in deviatoric stress with axial strain (Baraut soil at $12.0 \mathrm{~m}$ depth, $110 \mathrm{kPa}$ effective confining pressure and $1 \mathrm{~Hz}$ frequency). b Recorded and computed results of the variation in deviatoric stress with mean effective stress (Baraut soil at $12.0 \mathrm{~m}$ depth, $110 \mathrm{kPa}$ effective confining pressure and $1 \mathrm{~Hz}$ frequency). c Recorded and computed results of the variation in excess pore pressure ratio with number of cycles. (Baraut soil at $12.0 \mathrm{~m}$ depth, $110 \mathrm{kPa}$ effective confining pressure and $1 \mathrm{~Hz}$ frequency)

variation in PGA with depth (node number) for soils from Baraut, Noida and Mandi sites for scale-down Chamba earthquake is shown in Fig. 11. The range of PGA values for soils from Baraut site is $1.06 \times 10^{-3}-0.38 \mathrm{~g}$, for Noida site is $1.02 \times 10^{-4}-0.16 \mathrm{~g}$ and for Mandi site is $1.04 \times 10^{-4}-0.15 \mathrm{~g}$. The maximum PGA value is obtained at the Baraut site and the minimum at the Mandi site. This is because of the predominance of loose- to medium-dense sand in the Baraut site. Also, a comparison is made between the PGA values achieved from the dynamic analysis and the PGA values collected from the seismic recording stations located near this area. There is significant difference between the values of achieved and collected PGA for all the sites because of the decrease in stress factor and post-earthquake reorientation of intergranular soil particles. For the Baraut site, the increase in PGA is $130-340 \%$ compared to the PGA value in Mandi site.

The depthwise variation in PGD for the soils from Baraut, Noida and Mandi is shown in Table 4. The variation in displacement with time for Baraut site at the surface for Baraut earthquake $\left(M_{\mathrm{w}}=4.2\right)$ is given in Fig. 10b. The variation in PGD with depth (Node number) for Baraut, Noida and Mandi sites for scale-down Chamba earthquake is shown in Fig. 12. The ranges of PGD values for the soils are $4.68 \times 10^{-11}$ to $0.098 \mathrm{~m}$ for the Baraut site, $1.22 \times 10^{-13}$ to $0.045 \mathrm{~m}$ for the Noida site and $5.67 \times 10^{-13}$ to $0.040 \mathrm{~m}$ for the Mandi site. Higher PGD is obtained for Baraut site than for the Noida and Mandi sites, because of the predominance of loose- to medium-dense sand in Baraut site. For the Baraut site, the increase in PGD is about 111-145\% compared to that of the Mandi site.

Table 5 shows the depthwise variation in excess pore pressure ratio of soil from the sites of Baraut, Noida and Mandi. The range of excess pore pressure ratio for Baraut site is $0.10-0.98$, for Noida site is $0.08-0.90$ and for Mandi site is $0.10-0.73$. The excess pore pressure ratio value is highest for the Baraut site because of the predominance of loose- to medium-dense sand in soil strata.

\subsubsection{Comparison of the obtained PGA from this study with the reported PGA}

The results of the ground response analysis of this study are compared with the findings of the other reported studies. Thaker et al. [36] performed 1D analysis of soil from Gujarat. The variation in PGA value of the area was 0.09-0.22 g for SP-type soil. Anbazhagan et al. [3] performed ground response analysis for Bangalore city. The variation in PGA value was $0.10-0.15 \mathrm{~g}$ for SP-type soil. Chandrasekaran et al. [37] conducted dynamic site response analysis of Coimbatore City. The variation in PGA value was $0.08-0.22 \mathrm{~g}$ for SP-type soil. Roy and Sahu [38] conducted dynamic site response analysis for Kolkata city located in West Bengal. The variation in PGA value was 0.22-0.34 g for ML-type soil. Jishnu et al. [8] conducted dynamic site response analysis of soil for Kanpur city, located in Uttar Pradesh. The values of PGA, PGA and EPPR were 0.07-0.58 g, 0.0002-0.1604 $\mathrm{m}$ and 0.13-0.94, respectively, for SP- and ML-type soils. Naik and Choudhury [39] conducted dynamic site response analysis of Panjim City located in the Goa. The variation in PGA value was $0.05-0.22 \mathrm{~g}$ for ML-type soil. Kumar et al. [7] conducted 1D dynamic site response analysis for Guwahati region located in Assam. The variation in PGA values was 0.32-0.78 g for the ML-type soil. Naik et al. [9] conducted one- and two-dimensional dynamic site response analyses of soil for the sites of Rudrapur and Khatima located in the state of Uttarakhand. The variation in PGA value was 0.05 to $0.60 \mathrm{~g}$ for SP-, ML- and Cl-type soil. The variation in PGA from this study area is varying from $1.02 \times 10^{-4}$ to $0.38 \mathrm{~g}$. The variation is quite wide as the soil deposit is varying from poorly graded sand to silt of low plasticity. The variation in PGA from this study is lower than the reported studies in India for seismic zones III and IV.

\subsubsection{Comparison of liquefaction potential of soils with the reported studies}

The liquefaction analysis is carried out from CRR-CSRbased analysis as well as the EPPR obtained from 2D response analysis. The analysis is based on the EPPR value achieved from 2D response analysis. The soil layer is considered prone to liquefaction if the value of the EPPR exceeds 0.8 . It is observed that $1 \mathrm{D}$ dynamic response analysis gives overestimated results. Based on the oneand two-dimensional dynamic site response analyses, it is observed that the soil layer from $13.5 \mathrm{~m}$ to $15.0 \mathrm{~m}$ is prone to liquefaction for the Baraut site. For the Noida site, the soil layer from $10.5 \mathrm{~m}$ to $15.0 \mathrm{~m}$ is prone to liquefaction. These soil layers are prone to liquefaction because of the presence of loose sand. For the Mandi site, the soil layer is not prone to liquefaction.

The liquefaction potential of soils from this study has been compared with the reported results available for India (Table 6). Rao and Satyam [40] used shear wave velocity data for conducting one-dimensional dynamic site response analysis for the estimation of liquefaction 
Table 3 Consolidated result showing maximum acceleration values at different depths for Baraut, Noida and Mandi sites for all ground motion used in the present analysis

\begin{tabular}{|c|c|c|c|c|c|c|c|}
\hline & Layer & Outcrop & 4th layer & 8th layer & 16th layer & 24th layer & Base \\
\hline Earthquake motion & Site & $a_{\max (g)}$ & $a_{\max (\mathrm{g})}$ & $a_{\max (\mathrm{g})}$ & $a_{\max (\mathrm{g})}$ & $a_{\max (g)}$ & $a_{\max (\mathrm{g})}$ \\
\hline Baraut $\left(M_{\mathrm{w}} 4.5\right)$ & Baraut & $1.26 \times 10^{-3}$ (recorded-0.00842) & $1.06 \times 10^{-3}$ & $4.06 \times 10^{-3}$ & $2.52 \times 10^{-3}$ & $1.59 \times 10^{-3}$ & $2.59 \times 10^{-3}$ \\
\hline Chamba $\left(M_{\mathrm{w}}-5.1\right)$ & Baraut & 0.04 & 0.14 & 0.16 & 0.11 & 0.15 & 0.05 \\
\hline Chamoli $\left(M_{\mathrm{w}}-6.4\right)$ & Baraut & 0.25 & 0.36 & 0.26 & 0.26 & 0.20 & 0.26 \\
\hline Uttarkashi $\left(M_{\mathrm{w}}-6.5\right)$ & Baraut & 0.28 & 0.28 & 0.32 & 0.38 & 0.36 & 0.32 \\
\hline Noida $\left(M_{\mathrm{w}} 3.7\right)$ & Noida & $1.16 \times 10^{-4}($ recorded -0.0024$)$ & $1.01 \times 10^{-4}$ & $4.14 \times 10^{-4}$ & $2.2 \times 10^{-4}$ & $1.45 \times 10^{-4}$ & $1.8 \times 10^{-4}$ \\
\hline Chamba $\left(\mathrm{M}_{\mathrm{w}}-5.1\right)$ & Noida & 0.045 & 0.030 & 0.025 & 0.032 & 0.034 & 0.044 \\
\hline Chamoli $\left(M_{w}-6.4\right)$ & Noida & 0.160 & 0.044 & 0.030 & 0.038 & 0.040 & 0.160 \\
\hline Uttarkashi $\left(\mathrm{M}_{\mathrm{w}}-6.5\right)$ & Noida & 0.128 & 0.074 & 0.060 & 0.076 & 0.056 & 0.130 \\
\hline Mandi & Mandi & $1.04 \times 10^{-4}($ recorded-0.0022) & $1.25 \times 10^{-4}$ & $4.02 \times 10^{-4}$ & $2.84 \times 10^{-4}$ & $1.86 \times 10^{-4}$ & $1.6 \times 10^{-4}$ \\
\hline Chamba $\left(M_{\mathrm{w}}-5.1\right)$ & Mandi & 0.044 & 0.028 & 0.038 & 0.036 & 0.040 & 0.042 \\
\hline Chamoli $\left(M_{\mathrm{w}}-6.4\right)$ & Mandi & 0.160 & 0.046 & 0.058 & 0.054 & 0.044 & 0.155 \\
\hline Uttarkashi $\left(M_{\mathrm{w}}-6.5\right)$ & Mandi & 0.125 & 0.090 & 0.135 & 0.120 & 0.085 & 0.095 \\
\hline
\end{tabular}
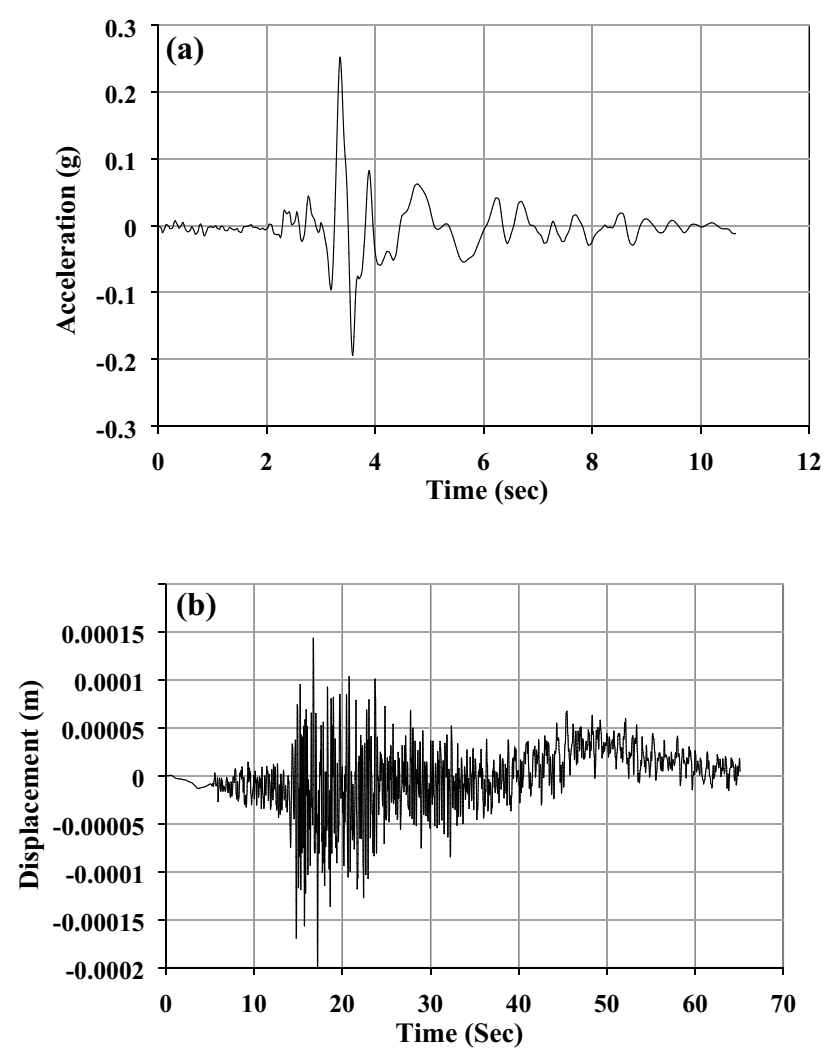

Fig. 10 a Variation in acceleration with time for Baraut site at surface for scale-down Chamba earthquake $\left(M_{\mathrm{w}}=5.1\right)$. b Variation in displacement with time for Baraut site at surface for Baraut earthquake $\left(M_{w}=4.2\right)$

potential of Delhi city for SP- and ML-type soil. It is observed that the soil layer from 6 to $12 \mathrm{~m}$ is prone to liquefaction. Vipin et al. [41] conducted probabilistic analysis using SPT-N data for the liquefaction analysis of SP-type

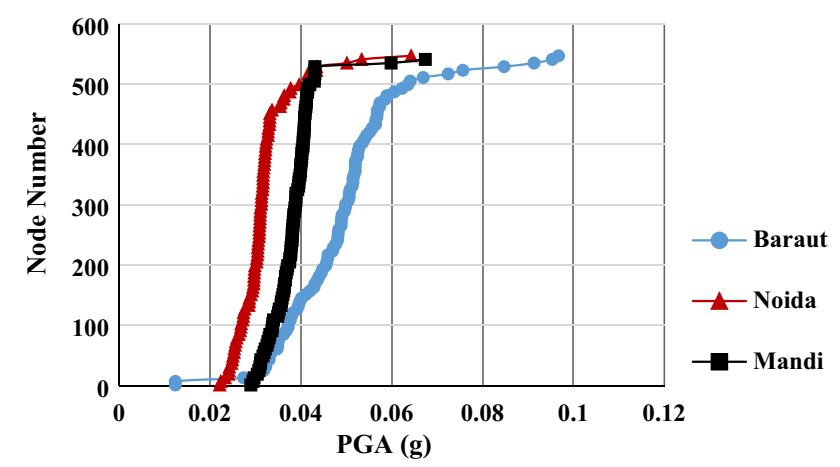

Fig. 11 Variation in peak ground acceleration (PGA) with node numbering for scale-down Chamba earthquake

soil from Bangalore city. The soil layer from 3 to $6 \mathrm{~m}$ is prone to liquefaction. Dixit et al. [42] conducted probabilistic analysis using SPT-N data for the liquefaction analysis of SP- and ML-type soils from Mumbai city. The soil layer from 6 to $9 \mathrm{~m}$ is prone to liquefaction. Muley et al. [43] used laboratory test and SPT-N data for the estimation of liquefaction potential for Roorkee region, Uttarakhand, for SP-type soil. The soil layer of depth $1.5 \mathrm{~m}-6 \mathrm{~m}$ is prone to liquefaction. Dwivedi et al. [44] used CRR-CSR-based method for the estimation of liquefaction potential for Ahmedabad city, Gujarat, for SP-type soil. The soil layer of depth $9 \mathrm{~m}-15 \mathrm{~m}$ is prone to liquefaction. Naik et al. [9] carried out $1 \mathrm{D}$ and $2 \mathrm{D}$ ground response analyses for the estimation of liquefaction potential of soils from Rudrapur and Khatima sites located in the state of Uttarakhand. The soil layer of depth $7 \mathrm{~m}-13 \mathrm{~m}$ is prone to liquefaction. Most of the previous studies reported that the soils from the respective sites are prone to liquefaction at shallow depth. However, the soils from the present study areas are 
Table 4 Consolidated result showing maximum displacement values at different depths for Baraut, Noida and Mandi sites for all ground motion used in the present analysis

\begin{tabular}{|c|c|c|c|c|c|c|c|}
\hline & Layer & Outcrop & 4th & 8th & 16th & 24th & Base \\
\hline $\begin{array}{l}\text { Earthquake } \\
\text { Motion }\end{array}$ & Site & $\begin{array}{l}\text { Displacement } \\
\text { (m) }\end{array}$ & $\begin{array}{l}\text { Displacement } \\
\text { (m) }\end{array}$ & $\begin{array}{l}\text { Displacement } \\
\text { (m) }\end{array}$ & $\begin{array}{l}\text { Displacement } \\
\text { (m) }\end{array}$ & $\begin{array}{l}\text { Displacement } \\
\text { (m) }\end{array}$ & Displacement (m) \\
\hline Baraut $\left(M_{\mathrm{w}} 4.5\right)$ & Baraut & $4.67 \times 10^{-11}$ & $1.24 \times 10^{-11}$ & $1.26 \times 10^{-11}$ & $6.8 \times 10^{-11}$ & $5.87 \times 10^{-11}$ & $4.62 \times 10^{-11}$ \\
\hline Chamba $\left(M_{\mathrm{w}}-5.1\right)$ & Baraut & 0.0057 & 0.012 & 0.011 & 0.008 & 0.008 & 0.0056 \\
\hline Chamoli $\left(M_{w}-6.4\right)$ & Baraut & 0.034 & 0.080 & 0.075 & 0.070 & 0.045 & 0.032 \\
\hline $\begin{array}{l}\text { Uttarkashi }\left(M_{w^{-}}\right. \\
\text {6.5) }\end{array}$ & Baraut & 0.092 & 0.095 & 0.090 & 0.098 & 0.095 & 0.090 \\
\hline Noida $\left(M_{\mathrm{w}} 3.7\right)$ & Noida & $1.22 \times 10^{-13}$ & $1.14 \times 10^{-12}$ & $1.08 \times 10^{-12}$ & $3.37 \times 10^{-12}$ & $1.29 \times 10^{-12}$ & $1.24 \times 10^{-12}$ \\
\hline Chamba $\left(M_{w}-5.1\right)$ & Noida & 0.0012 & 0.0014 & 0.0006 & 0.0008 & 0.0008 & 0.0011 \\
\hline Chamoli $\left(M_{w}-6.4\right)$ & Noida & 0.006 & 0.011 & 0.008 & 0.010 & 0.012 & 0.006 \\
\hline $\begin{array}{l}\text { Uttarkashi }\left(M_{w^{-}}\right. \\
\text {6.5) }\end{array}$ & Noida & 0.040 & 0.041 & 0.038 & 0.041 & 0.039 & 0.040 \\
\hline Mandi & Mandi & $5.67 \times 10^{-13}$ & $1.14 \times 10^{-12}$ & $1.13 \times 10^{-12}$ & $7.7 \times 10^{-12}$ & $3.89 \times 10^{-12}$ & $5.47 \times 10^{-12}$ \\
\hline Chamba $\left(M_{\mathrm{w}}{ }^{-5.1}\right)$ & Mandi & 0.0012 & 0.0013 & 0.0011 & 0.0013 & 0.0011 & 0.0012 \\
\hline Chamoli $\left(M_{w}-6.4\right)$ & Mandi & 0.0055 & 0.021 & 0.018 & 0.014 & 0.009 & 0.006 \\
\hline $\begin{array}{l}\text { Uttarkashi }\left(M_{\mathrm{w}^{-}}\right. \\
6.5)\end{array}$ & Mandi & 0.041 & 0.045 & 0.042 & 0.040 & 0.041 & 0.040 \\
\hline
\end{tabular}

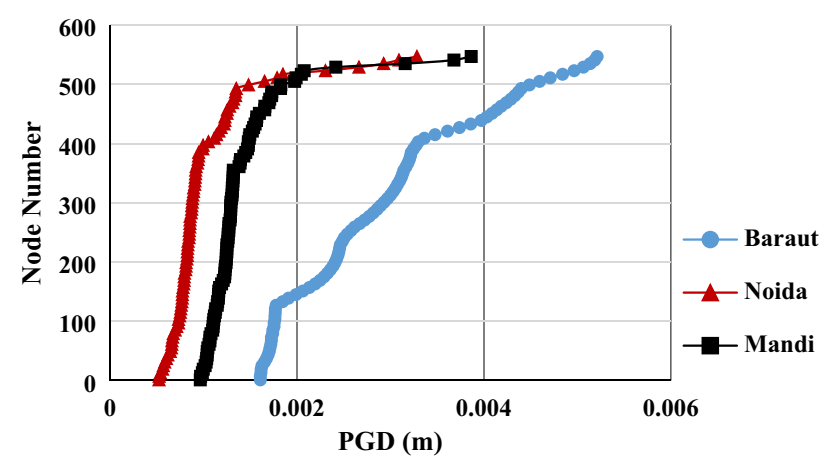

Fig. 12 Variation in peak ground displacement (PGD) with node numbering for scale-down Chamba earthquake

prone to liquefaction at $10 \mathrm{~m}-15 \mathrm{~m}$ from ground surface (medium depth). Ideally, stone columns or deep compaction techniques may be preferred to mitigate liquefaction in this study area.

\section{Conclusions}

Detailed field tests and geotechnical tests were conducted on soils from the Baraut, Noida and Mandi sites. Straincontrolled cyclic triaxial tests have been performed on undisturbed and disturbed soil samples collected from these sites. The results of the field and laboratory tests were used for performing dynamic response analysis (1D and 2D). 2D response analysis was performed for better prediction of earthquake-induced damage in terms of parameters such as PGA, PGD and EPPR. The following conclusions are drawn from the study.

- The soils collected from the three sites consist of poorly graded sand and silt. From the SPT-N value, it is observed that soils are either in a loose- or mediumdense state. The required number of cycles for the initial liquefaction of the soil collected from Baraut site is about $5 \%$ to $42 \%$ higher as compared to the soil collected from Noida and Mandi sites. It is observed that the maximum spectral velocity and spectral acceleration are achieved for Uttarkashi earthquake.

- The response analysis reveals that the soil from Baraut site shows higher values of PGA and PGD values than the soil from the Noida and Mandi sites due to the predominance of sand layer of loose to medium density at the Baraut site. The variation in PGA from this study is lower than the reported studies in India for seismic zones III and IV.

- The liquefaction potential of soils from this study area has been compared with the reported results adjoining to Indo-Gangetic plain. Most of the previous studies reported that the soils from the respective sites are prone to liquefaction at shallow depth. However, the soil samples from the present study areas are prone to liquefaction at $10 \mathrm{~m}$ to $15 \mathrm{~m}$ from ground surface (medium depth).

- The experimental investigations and response analysis of the soils in these areas will be helpful to take preventive measures against liquefaction. The findings from 
Table 5 Consolidated result showing maximum excess pore pressure ratio values at different depths for Baraut, Noida and Mandi sites for all ground motion used in the present analysis

\begin{tabular}{|c|c|c|c|c|c|c|c|c|c|}
\hline \multirow[t]{2}{*}{ Earthquake motion } & \multirow[t]{2}{*}{ Site } & \multicolumn{8}{|l|}{ Layers } \\
\hline & & $\operatorname{EPPR}(9 \mathrm{~m})$ & EPPR (12 m) & EPPR (15 m) & EPPR (18 m) & EPPR (21 m) & $\operatorname{EPPR}(24 \mathrm{~m})$ & $\operatorname{EPPR}(27 \mathrm{~m})$ & EPPR (30 m) \\
\hline Baraut $\left(M_{\mathrm{w}}-4.5\right)$ & Baraut & 0.68 & 0.71 & 0.66 & 0.10 & 0.16 & 0.35 & 0.52 & 0.65 \\
\hline Chamba $\left(M_{\mathrm{w}}-5.1\right)$ & Baraut & 0.82 & 0.92 & 0.90 & 0.08 & 0.18 & 0.44 & 0.64 & 0.88 \\
\hline Chamoli $\left(M_{w}-6.4\right)$ & Baraut & 0.82 & 0.92 & 0.98 & 0.08 & 0.24 & 0.60 & 0.80 & 0.86 \\
\hline Uttarkashi $\left(M_{\mathrm{w}}-6.5\right)$ & Baraut & 0.64 & 0.75 & 0.96 & 0.10 & 0.12 & 0.30 & 0.51 & 0.77 \\
\hline Noida $\left(M_{\mathrm{w}}-3.7\right)$ & Noida & 0.66 & 0.72 & 0.65 & 0.06 & 0.16 & 0.32 & 0.40 & 0.60 \\
\hline Chamba $\left(M_{\mathrm{w}}-5.1\right)$ & Noida & 0.83 & 0.90 & 0.80 & 0.08 & 0.20 & 0.40 & 0.56 & 0.74 \\
\hline Chamoli $\left(M_{w}-6.4\right)$ & Noida & 0.83 & 0.90 & 0.80 & 0.08 & 0.20 & 0.40 & 0.56 & 0.74 \\
\hline Uttarkashi $\left(M_{\mathrm{w}}-6.5\right)$ & Noida & 0.83 & 0.90 & 0.80 & 0.08 & 0.20 & 0.40 & 0.56 & 0.74 \\
\hline Mandi & Mandi & 0.52 & 0.56 & 0.54 & 0.15 & 0.16 & - & - & - \\
\hline Chamba $\left(M_{\mathrm{w}}-5.1\right)$ & Mandi & 0.63 & 0.73 & 0.66 & 0.10 & 0.14 & - & - & - \\
\hline Chamoli $\left(M_{w}-6.4\right)$ & Mandi & 0.63 & 0.73 & 0.66 & 0.08 & 0.12 & - & - & - \\
\hline Uttarkashi $\left(M_{\mathrm{w}}-6.5\right)$ & Mandi & 0.65 & 0.71 & 0.69 & 0.10 & 0.14 & - & - & - \\
\hline
\end{tabular}

Table 6 Comparison of liquefaction potential of soils from the present study area with the reported studies available for India

\begin{tabular}{llllll}
\hline SI no & Author & Year & Study area & Soil type & Liquefiable depth (m) \\
\hline 1 & Rao and Satyam & 2007 & Delhi city & SP and ML & $6-12$ \\
2 & Vipin et al. & 2010 & Bangalore city & SP & $3-6$ \\
3 & Dixit et al. & 2012 & Mumbai city & SP and ML & $6-9$ \\
4 & Muley et al. & 2015 & Roorkee, Uttarakhand & SP & $1.5-6$ \\
5 & Dwidevi et al. & 2017 & Ahmedabad city, Gujarat & SP & $9-15$ \\
6 & Naik et al. & 2019 & Rudrapur and Khatima, Uttarakhand & SP, ML and Cl & $7-13$ \\
7 & Present study & 2020 & Baraut, Noida and Mandi & SP and ML & $13.5-15$ (Baraut) \\
& & & & & $10.5-15$ (Noida) \\
& & & & None (Mandi) \\
\hline
\end{tabular}

this study will be useful in design of structures on shallow as well as deep foundations.

Acknowledgement Authors are grateful to the Board of Research in Nuclear Sciences (BRNS), India, for providing financial assistance for this present study (No. 2013/36/69-BRNS/ 2463).

\section{Compliance with ethical standards}

Conflict of interest On behalf of all authors, the corresponding author states that there is no conflict of interest.

Open Access This article is licensed under a Creative Commons Attribution 4.0 International License, which permits use, sharing, adaptation, distribution and reproduction in any medium or format, as long as you give appropriate credit to the original author(s) and the source, provide a link to the Creative Commons licence, and indicate if changes were made. The images or other third party material in this article are included in the article's Creative Commons licence, unless indicated otherwise in a credit line to the material. If material is not included in the article's Creative Commons licence and your intended use is not permitted by statutory regulation or exceeds the permitted use, you will need to obtain permission directly from the copyright holder. To view a copy of this licence, visit http://creativecommons .org/licenses/by/4.0\%.

\section{References}

1. List of 21 st-century earthquakes, Wikipedia (Home page: https ://en.wikipedia.org/wiki/List_of_21st-century_earthquakes)

2. Kandpal GC, John B, Joshi KC (2009) Geotechnical studies in relation to seismic microzonation of Union Territory of Chandigarh. J Indian Geophys Union 13(2):75-83

3. Anbazhagan P, Thingbaijam KKS, Nath SK, Kumar JNN, Sitharam TG (2010) Multi-criteria seismic hazard evaluation for Bangalore city, India. J Asian Earth Sci 28:186-198

4. Sharma B, Rahman SK, Saikia BD (2013) Use of contour maps for preliminary assessment of subsoil of Guwahati city. In: Proceedings of Indian Geotechnical Conference, Roorkee

5. Wiemer S, Garcia FM, Burg JP (2009) Development of a seismic source model for probabilistic seismic hazard assessment of 
nuclear power plant sites in Switzerland: the view from PEGASOS Expert Group. Swiss J Geosci 102(1):189-209

6. Rao HC, Ramana GV (2010) Site specific ground response analysis at Delhi, India. Electron J Geotech Eng 14(D):1-16

7. Kumar SS, Krishna AM, Dey A (2014) Non-linear site specific ground response analysis: case study of Amingaon, Guwahati. In: Proceedings of 15th Symposium in Earthquake Engineering

8. Jishnu R, Naik SP, Patra NR, Malik JN (2013) Ground response analysis of Kanpur soil along Indo-Gangetic plains. Soil Dyn Earthq Eng 51:47-57

9. Naik SP, Kundu A, Patra NR, Bandopadhaya S, Reddy GR (2019) Earthquake response analysis of soils fromRudrapur and Khatima sites adjacent toHimalayan Frontal Thrust (HFT) using field andlaboratory-derived dynamic soil properties. J Earthq Eng. https://doi.org/10.1080/13632469.2019.1695691

10. Prasad RK, Sharma A (2015) Ground water year book of Uttar Pradesh. Technical report prepared by Central Ground Water Board, Ministry of Water Resources, River Development and Ganga Rejuvenation, Government of India

11. Bhatti R (2017) Ground water year book of Himachal Pradesh. Technical report prepared by Central Ground Water Board, Ministry of Water Resources, River Development and Ganga Rejuvenation, Government of India

12. IS 2131 (1981) Method for standard penetration test for soils. Bureau of Indian Standards, New Delhi, India

13. ASTM D1586-11 (2011) Standard test method for standard penetration test (SPT) and split barrel sampling of soils. American Society of Testing and Materials, West Conshohocken, Pennsylvania, USA

14. ASTM D7400 - 08 (2008) Standard test methods for downhole seismic testing. American Society of Testing and Materials, West Conshohocken, Pennsylvania, USA

15. IS 1498 (1970) Classification and identification of soils for general engineering purposes. Bureau of Indian Standards, New Delhi, India

16. ASTM D2487-11 (2011) Standard practice for classification of soils for engineering purposes (unified soil classification system). American Society of Testing and Materials, West Conshohocken, PA, USA

17. IS 2720 (1980) Methods of test for soils, part 3: Determination of specific gravity. Bureau of Indian Standards, New Delhi, India

18. IS 2720 (1985) Methods of test for soils, part 4: Grain size analysis. Bureau of Indian Standards, New Delhi, India

19. IS 2720 (1985) Methods of test for soils, part 5: Determination of liquid limit and Plastic limit. Bureau of Indian Standards, New Delhi, India

20. IS 2720 (1986) Methods of test for soils, part 15: determination of consolidation properties. Bureau of Indian Standards, New Delhi, India

21. IS 2720 (1993) Methods of test for soils, part 11: Determination of the shear strength parameters of a specimen tested in unconsolidated undrained triaxial compression without the measurement of pore water pressure. Bureau of Indian Standards, New Delhi, India

22. Ladd RS (1978) Preparing test specimens using under compaction. Geotech Test J ASTM 1(1):16-23

23. Mulilis JP, Arulanandan K, Mitchell JK, Chan CK, Seed HB (1977) Effects of sample preparation on sand liquefaction. J Geotech Engg Div 103(2):91-108

24. HEICO cyclic-static triaxial testing. Home page: http://www. heicoin.com/products

25. ASTM D5311-M13. Standard test method for load controlled cyclic triaxial strength of soil. American Society of Testing and Materials, West Conshohocken, Pennsylvania, USA

26. Seed HB, Idriss IM (1971) Simplified procedure for evaluating soil liquefaction potential. J Soil Mech Found Div ASCE 97(9):1249-1273
27. Fenves GL, McKenna F, Mazzoni S (2007) OpenSees command language manual. University of California at Berkeley, California, USA

28. Biot MA (1962) The mechanics of deformation and acoustic propagation in porous media. J Appl Phys 33:1482-1498

29. Lysmer J, Kuhlemeyer RL (1969) Finite dynamic model for infinite media. J Eng Mech Div ASCE 95(4):859-877

30. Prevost JH (1985) A simple plasticity theory for frictional cohesionless soils. Soil Dyn Earthq Eng 4(1):9-17

31. Parra E (1996) Numerical modelling of liquefaction and lateral ground deformation including cyclic mobility and dilative behaviour of soil systems. Ph.D. Thesis, Department of Civil Engineering, Rensselaer Polytechnic Institute, Troy, New York, USA

32. Yang (2000) Numerical modelling of earthquake site response including dilation and liquefaction. Ph.D. Thesis, Department of Civil Engineering and Engineering Mechanics, Columbia University, New York, USA

33. Yang Z, Lu J, Elgamal A (2008) OpenSees soil models and solid fluid fully coupled elements. OpenSees user's manual. University of California at Berkeley, California, USA

34. Kuhlemeyer RL, Lysmer J (1973) Finite element method accuracy for wave propagation problems. J Soil Mech Found Div ASCE 99(5):421-427

35. Mohanty S, Patra NR (2016) Dynamic response analysis of Talcher pond ash embankment in India. Soil Dyn Earthq Eng $84: 238-250$

36. Thaker TP, Rao KS and Gupta KK (2009) One dimensional analysis of coastal soil near Naliya, Kutch, Gujarat. In: Proceedings of Indian Geotechnical Conference, December 2009, Guntur, India

37. Chandrasekaran SS, Bhardwaj GS, Dutt HH (2012) Seismic ground response analysis for a site in Coimbatore. In: Proceedings of ISET Golden Jubilee Symposium, Indian Society of Earthquake Technology, IIT Roorkee, Roorkee

38. Roy N, Sahu RB (2012) Site specific ground motion simulation and seismic response analysis for microzonation of Kolkata. Geomech Eng 4(1):1-18

39. Naik NP and Choudhury D (2013) Site specific ground response analysis for typical sites for typical sites in Panjim city, Goa. In: Proceedings of Indian Geotechnical Conference, December 2013, Roorkee, India

40. Rao KS, Satyam ND (2007) Liquefaction studies for seismic microzonation of Delhi region. Current Sci 92(5):646-654

41. Vipin KS, Sitharam TG, Anbazhagan P (2009) Probabilistic evaluation of seismic soil liquefaction potential based on SPT data. Nat Hazards 53:547-560

42. Dixit J, Dewaikar DM, Jangid RS (2012) Assessment of liquefaction potential index for Mumbai City. Nat Hazards Earth Syst Sci 12:2759-2768

43. Muley P, Maheshwari BK, Paul DK (2015) Liquefaction potential of Roorkee region using field and laboratory tests. Int J Geosynth Ground Eng 1(37):36-49

44. Dwivedi VK, Dubey RK, Thockhom S, Pancholi V, Chopra S, Rastogi BK (2017) Assessment of liquefaction potential of soil in Ahmedabad region, Western India". J Indian Geophys Union 21(2):116-123

Publisher's Note Springer Nature remains neutral with regard to jurisdictional claims in published maps and institutional affiliations. 